\title{
Guideline adherence and control of diabetes mellitus with or without co-morbidities in various wards of a tertiary hospital Malaysia
}

\author{
*Muhammad Zahid Iqbal', Muhammad Shahid Iqbal', Dayana Nicholas ${ }^{1}$, Jamaluddin Awang1, Amer Hayat Khan², \\ Syed Azhar Sulaiman ${ }^{2}$ \\ ${ }^{1}$ Department of Clinical Pharmacy and Pharmacy Practice, Faculty of Pharmacy, AIMST University Malaysia \\ ${ }^{2}$ Department of Clinical Pharmacy, School of Pharmaceutical Sciences, Universiti Sains Malaysia
}

\begin{abstract}
To assess the adherence of physicians involved in the management of diabetes mellitus with or without co-morbidities with reference to Clinical Practice Guideline 2009given by Ministry of Health Malaysia in the tertiary care hospital, Pinang General Hospital Malaysia. Cross-sectional study was done at tertiary care hospital, Penang, Malaysia. The total 51physicians and 1020 patient's prescriptions written by same physicians were taken from the record of the Penang General Hospital (20 prescriptions for each enrolled physician). All 1020 patients were suffering from diabetes mellitus with or without co-morbidities. These patients were recruited from the different wards of the Penang General Hospital. Depending on the recommendations of CPG 2009 the prescriptions of patients were divided into adherent and non-adherent prescriptions. The overall good level of physician adherence was seen with respect to the recommendations of CPG2009 in all prescriptions. A statistically significant negative association $(\Phi=0.094$, pvalue $=0.003$ ) was observed between diabetes mellitus control and co-morbidities. CPG adherent had statistically weak negative association $(\Phi=-0.081$, p-value $=0.010)$ with patients having co-morbidities. No statistically significant association was observed between CPG adherence and any other co-morbidity. The study explored the several features of prescription pattern of physicians involved in the management of diabetes mellitus with or without co-morbidities and recognized the need for improvement in their prescription pattern for treating the diabetes mellitus.
\end{abstract}

Key Words: Outcomes, Attitude, Management, Prescribers, Treatment recommendations, Compliance therapy.

\section{INTRODUCTION}

Diabetes mellitus is a common chronic disorder characterized by chronic hyperglycemia together with other metabolic abnormalities (WHO 2003). It is due to insulin resistance or deficiency with increased hepatic glucose output (Alberti Zimmet, 1998; Malaysian Diabetes mellitus Guidelines, 2009). Diabetes mellitus is a chronic illness that involves long-lasting medical care and constant patient self-management education and support to prevent acute complications and to decrease the risk of long-term complications (Nazimek-Siewniak et al., 2002). Diabetes mellitus if not treated properly it can cause various complications in patients. Diabetes and its complications make up a major public health problem all over the world and are a main cause of morbidity and mortality (WHO 1999). In actual fact, diabetes has reached epidemic proportions all over the world (Agrawal et al., 2011). Uncontrolled diabetes is resulted in increased risk of microvascular and macrovascular complications (Nathan et al., 2009; Nazimek-Siewniak et al., 2002).

Co-morbidity, described as the presence of other chronic conditions in the same person along with an index-disease, occurs normally among patients with diabetes. The patient of diabetes often suffers from one or more co-morbidities (Beckman Ja 2002). On the other hand, patients with diabetes have both the diabetes related as well as non-diabetes related co-morbidities. A lot of co-morbidities are present with Diabetes mellitus. These co-morbidities mainly contain the single co-
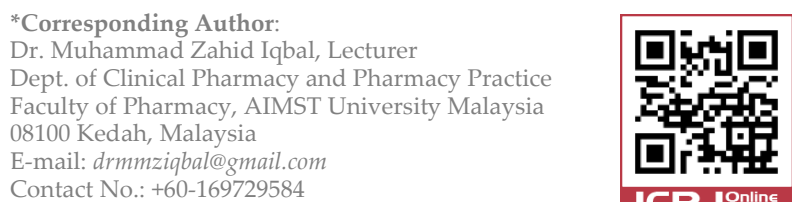

morbidity as well as multiple co-morbidities (Struijset al., 2006). The tight control of DM and appropriate management of these co-morbidities is required to increase the quality of life of patients and decrease further complications in patients (Arauz-Pacheco et al., 2002; Heisleret al., 2002). The important co-morbidities contain hypertension, dislipidemia, renal diseases and obesity.

The results of National Health and Morbidity Survey 2011 (NHMS 2011), shows that diabetes prevalence in persons with aged 30 years and above has been augmented $40 \%$ in the previous five years, from $14.9 \%$ in 2006 to $20.8 \%$ in 2011, with the raise mainly contributed by the increased percentage of "undiagnosed diabetes" at $8 \%$. The survey in Malaysia was also shown that the occurrence of diagnosed diabetes is somewhat elevated in rural areas at $15.5 \%$, In contrast to urban areas at $15.1 \%$ (Ministry of Health, Malaysia 2011).

Various studies have been conducted to identify factors liable for poor control of DM. These factors including the patient related factors, physician related factors and health care system related factors (Chatterjee, 2006; Khattab et al., 2010; Furthauer et al., 2013). Most important patient related factors consist of non-adherence to medication recommendations, knowledge about disease, attitude towards the disease and risk factors associated with disease (Satman et al., 2012; Ahmad et al., 2012).

Physician related factors include the knowledge of physician about guidelines, attitude of doctors towards the recommendations of guidelines, overestimation of provided treatment, failure to motivate patients participate in achieving the control of DM (Khattab et al., 2010). System related factors include non-access to health system, patient provider relations and practice scenarios (Khattab et al., 2010). 
Table 1: Social and demographic characteristics of patients studied $(\mathrm{n}=1020)$.

\begin{tabular}{ll}
\hline Variables & n (Percentage) \\
\hline Gender & $496(48.6)$ \\
Male & $524(51.4)$ \\
Female & \\
Ethnicity & $462(45.3)$ \\
Malay & $357(35.0)$ \\
Chinese & $177(17.4)$ \\
Indian & $24(2.4)$ \\
Others & \\
Age (years) & $77(7.5)$ \\
Less than 30 years & $154(15.1)$ \\
31-40 years & $200(19.6)$ \\
41-50 years & $589(57.7)$ \\
More than 51 years & \\
Family history & $376(36.9)$ \\
Don't have & $416(40.8)$ \\
Diabetes & $112(11.0)$ \\
Hypertension & $63(6.2)$ \\
Dyslipidemia & $53(5.1)$ \\
Renal disease &
\end{tabular}

Mean age: $53.89 \pm 15.52$; SD: Standard deviation

\section{MATERIALS AND METHODS}

The current study was correlational observational study. Fifty one physicians including $21(41.2 \%)$ from diabetes, $17(33.3 \%)$ from medicine, 7 (13.7\%) from hypertension, 4 (7.8\%) from nephrology and 2 (3.9\%) from cardiology wards, who had given written consent to participate were enrolled in present study. In order to evaluate the prescription pattern of each enrolled physician convenience sample of 20 patients, a total of 1020 prescriptions of established diabetic patients $(20$ prescriptions per physician) were enrolled in current study. The prescriptions written by enrolled physicians were taken from record of Penang General Hospital. The enrolled physicians were involved in the treatment of diabetes mellitus (with or without co-morbidities).

A validated tool was used to collect the sample size of the study. In order to find adherence and nonadherence of prescribers with or without co-morbidities, a detailed review of patient medical record was conducted. Adverse drug reactions, contraindications were noted. The prescribed drugs were noted by their generic names. The collected prescriptions were classified as adherent and non-adherent with CPG 2009 on the basis of criteria developed from the guideline. A score of 1 was credited to each adherent prescription (prescription in compliance with clinical practice guideline 2009) whereas zero was credited to each non-adherent prescription. Current study was approved by the Ministry of Health Medical Research Ethics Committee Malaysia (Ref: KKM/NIHSEC/08/0804/P12-606).

Statistical analyses were calculated using SPSS, version 20. Pearson's chi-square was used to test for significance differences between variables. $p$-Values $\leq 0.05$ were considered statistically significant. Cramer's value and Phi value was calculated to find the statistical significance between variables.

\section{RESULTS}

From total 1020 established diabetic patients 496 (48.6\%) were male and $524(51.4 \%)$ were female. Mean age of the patients were $53.89 \pm 15.52$ years. Five hundred and eighty nine $(57.7 \%)$ patients were having age more than 51 years. The study sample was ethnically diverse consisted of
Table 2: Co-morbidities of patients studied $(n=1020)$.

\begin{tabular}{ll}
\hline Co-morbidity & No. (Percentage) \\
\hline Without co-morbidity & $313(30.6)$ \\
Hypertension & $290(28.4)$ \\
Dyslipidemia & $173(16.9)$ \\
Obesity & $146(13.7)$ \\
Renal disease & $66(6.4)$ \\
Coronary Heart Disease (CHD) & $32(4.0)$ \\
\hline
\end{tabular}

Malay $45.3 \%(n=462)$, Chinese $35.0 \%(n=357)$, Indian $17.4 \%$ $(\mathrm{n}=177)$ and others $2.4 \% \quad(\mathrm{n}=24)$. Only $40.8 \% \quad(\mathrm{n}=416)$ patient were having positive family history of diabetes mellitus (table 1).

The majority $707(69.3 \%)$ of the patients were suffering from co-morbidities. The most of the patients were having single co-morbidity. Only $7.5 \% \quad(n=76)$ patients were having multiple co-morbidities. They are of diabetes along with hypertension and dyslipidemia. Table 2 shows the different percentages of various co-morbidities present along with the diabetes mellitus in the selected sample size of the patients.

The patients with no co-morbidity were having more control on the disease and vice versa. On the other way the patient with renal diseases were having less control on diabetes mellitus. A statistically significant negative association $(\Phi=0.094, p$-value $=0.003)$ was observed between diabetes mellitus control and co-morbidities. Thus it means that the patients suffering from comorbidities will have less control on diabetes mellitus and vice versa. No statistically significant association was observed between diabetes mellitus control and any other variables (table 3 ).

In Penang General Hospital, the patients without comorbidities were receiving more adherent therapy with CPG 2009. In contrast the patients with renal diseases were receiving less adherent therapy for diabetes mellitus with CPG 2009. CPG adherent had statistically weak negative association $(\Phi=-0.081, p$-value $=0.010)$ with patients having co-morbidities. Thus the results of the current study show that the patients with co-morbidities were receiving less adherence therapy. In contrast the patients without co-morbidities were receiving more adherence therapy according to the Clinical Practice Guideline 2009. In other words the adherence of clinical practice guideline was decreasing with increasing in the co-morbidities. No statistically significant association was observed between CPG adherence and any other comorbidity (table 4).

\section{DISCUSSION}

Studies conducted elsewhere in past had drawn different results regarding the adherence of doctors with the diabetes guidelines. Some studies reported good adherent of doctors with guidelines (Khan et al., 2010; Peimani et al. 2010; Schoenfeld et al., 2001; Ward et al., 2002), whereas the others concluded non-adherence of doctors (Coon Zulkowski, 2002; Kirkman et al., 2002).

The present study was conducted in the different wards of Penang General Hospital for evaluate the adherence of doctors in different ward and with different co-morbidities. The adherence of doctors on treatment recommendations cannot evaluate by the simple survey base study. In a review article where 139 studies were analyzed, 73 clinical outcomes are considered for evaluation of the actual practice. This review study shows results quite similar in respect of the adherence and 
Table 3: Cross tabulation between DM control and comorbidities in patients.

\begin{tabular}{|c|c|c|c|}
\hline Variables & $\begin{array}{c}\text { DM control } \\
\text { n (Percentage) }\end{array}$ & $p$-value* & $\begin{array}{l}\text { Effect } \\
\text { size }^{* *}\end{array}$ \\
\hline $\begin{array}{l}\text { Co-morbidities } \\
\text { Yes } \\
\text { No }\end{array}$ & $\begin{array}{l}435(61.5) \\
223(71.2)\end{array}$ & 0.003 & -0.094 \\
\hline $\begin{array}{l}\text { Hypertension } \\
\text { Yes } \\
\text { No }\end{array}$ & $\begin{array}{l}154(61.6) \\
504(65.5)\end{array}$ & 0.268 & - \\
\hline $\begin{array}{l}\text { Dyslipidemia } \\
\text { Yes } \\
\text { No }\end{array}$ & $\begin{array}{c}89(62.2) \\
569(64.9)\end{array}$ & 0.540 & - \\
\hline $\begin{array}{l}\text { Obesity } \\
\text { Yes } \\
\text { No }\end{array}$ & $\begin{array}{c}93(66.4) \\
565(64.2)\end{array}$ & 0.609 & - \\
\hline $\begin{array}{l}\text { Renal disease } \\
\text { Yes } \\
\text { No }\end{array}$ & $\begin{array}{c}36(54.5) \\
622(65.2)\end{array}$ & 0.080 & - \\
\hline $\begin{array}{l}\text { Coronary heart disease } \\
\text { CHD) } \\
\text { Yes } \\
\text { No }\end{array}$ & $\begin{array}{c}19(59.4) \\
639(64.7)\end{array}$ & 0.537 & - \\
\hline
\end{tabular}

outcomes. There was about $67-76 \%$ of the results shows the adherence with treatment recommendations (Cramer et al., 2008). None of the above mention studies evaluated the adherence of doctors in various co-morbidities. The selected wards were containing: diabetes ward, medicine wards, hypertension ward, nephrology and cardiology.

Current study differentiated from the previous studies discussed above in the field of co-morbidity. The Present study also evaluates the doctors' adherence with co-morbid conditions. The patients who were suffering from comorbidities were more likely to receive compliance therapy as compared with the diabetic patients without comorbidity. The reason of poor adherence of doctors without co-morbidity is seems to be their poor knowledge on recommendations of guideline. The Present study evaluates the knowledge of doctors on five types of co-morbidities of diabetes mellitus. They include hypertension, dyslipidemia, Coronary Heart Disease (CHD) and renal diseases.

In hypertension with diabetes mellitus the adherence of doctors were about $70.4 \%$. This adherence is more as compared with the previous studies (Coon Zulkowski, 2002; Nau et al., 2005; Ahmad et al., 2012). As doctors' adherence with guidelines recommendations was evaluated by noting their actual prescribing practices, it is more rational to compare our results with studies which have used the same strategy. Almost similar findings were reported by a cross-sectional study conducted at a family medicine clinic in Edmonton, where $64 \%$ of diabetic or renal disease patients and $58 \%$ of cerebrovascular disease patients were receiving Canadian Hypertension Education Program recommended therapy (Houlihan et al., 2009). The patients were receiving compliance therapy in the dyslipidemia. The total guideline adherence of doctors was $71.3 \%$ in the management of dyslipidemia along with diabetes mellitus. The results of the current study is quite similar with the study conducted in Penang General Hospital which shows adherence $67 \%$ in the cardiology ward of Penang General Hospital (Ahmad, Nafees et al., 2012). The guideline adherence of doctors on Coronary Heart Disease was about $65.6 \%$. This percentage of adherence was quite low with reference to the other co-morbidities.
Table 4: Cross tabulation between CPG adherence and comorbidities.

\begin{tabular}{|c|c|c|c|}
\hline Variables & $\begin{array}{c}\text { DM control } \\
\text { n (Percentage) }\end{array}$ & $p$-value ${ }^{*}$ & $\begin{array}{l}\text { Effect } \\
\text { size }\end{array}$ \\
\hline $\begin{array}{l}\text { Co-morbidities } \\
\text { Yes } \\
\text { No }\end{array}$ & $\begin{array}{l}503(71.1) \\
347(78.9)\end{array}$ & 0.010 & -0.081 \\
\hline $\begin{array}{l}\text { Hypertension } \\
\text { Yes } \\
\text { No }\end{array}$ & $\begin{array}{l}176(70.4) \\
574(74.5)\end{array}$ & 0.197 & - \\
\hline $\begin{array}{l}\text { Dyslipidemia } \\
\text { Yes } \\
\text { No }\end{array}$ & $\begin{array}{l}102(71.3) \\
648(73.9)\end{array}$ & 0.520 & - \\
\hline $\begin{array}{l}\text { Obesity } \\
\text { Yes } \\
\text { No }\end{array}$ & $\begin{array}{l}107(76.4) \\
643(73.1)\end{array}$ & 0.403 & - \\
\hline $\begin{array}{l}\text { Renal disease } \\
\text { Yes } \\
\text { No }\end{array}$ & $\begin{array}{c}45(68.2) \\
705(73.9)\end{array}$ & 0.309 & - \\
\hline $\begin{array}{l}\text { Coronary heart disease } \\
\text { (CHD) } \\
\text { Yes } \\
\text { No }\end{array}$ & $\begin{array}{c}21(65.6) \\
729(73.8)\end{array}$ & 0.303 & - \\
\hline
\end{tabular}

The possible reason for this poor adherence might be the poor adherence of doctors towards the CPG 2009 and the other possible reason for poor adherence can be the non availability of specialists and consultants in the ward of the diabetes as well as cardiology (Ahmad et al., 2012). The medical officers and house officers might be not discussed the cases with the specialists and consultants. As a result poor adherence of the guideline was observed as compared with the other co-morbidities (Ahmad et al., 2012).

The patients were getting less adherent therapy as compared with the other co-morbid conditions. The adherence of doctors on renal diseases was about $68.2 \%$. This percentage of adherence was quite low with reference to the other co-morbidities and quite high from the Coronary Heart Disease. The probable cause for this poor adherence might be the poor adherence of doctors towards the CPG 2009 and the other feasible reason for poor adherence can also be the non-availability of specialists and consultants in the ward of the diabetes as well as nephrology (Ahmad et al., 2012). As a result poor adherence of guideline was seen as compared with the other co-morbidities.

Positive control of diabetes mellitus was seen in current study. In the present study about $65 \%$ control was seen in patients with diabetes mellitus. This control was different in male and female. In males, the control of diabetes mellitus was $61.3 \%$, whereas, in females, this control was about $67.7 \%$. This control of diabetes mellitus was quite different from the multi-center studies conducted in past in Malaysia where the control was reported as only about 40\% (Chuang et al., 2002; Yun et al., 2007).

The better control of the diabetes mellitus in a current study was seemed to be due to the better knowledge of doctors and good adherence of doctors on the recommendations of CPG 2009. The majority of the patients were with co-morbidity and in co-morbid condition; the patient needs more compliance and aggressive therapy. The doctors often pay more attention for the patients with co-morbid conditions and patients also became more aware with the diabetes mellitus control. Thus the control of diabetes mellitus became more in co-morbid conditions (Redekop et al., 2002; Piette Kerr, 2006; Struijs et al., 2006; Wexler et al., 
2006; Wermeling et al., 2012). The findings of these studies show that the control of diabetes mellitus is more with the co-morbid conditions in patients with diabetes mellitus.

The other possible reason for the control of diabetes mellitus in patients with or without co-morbidities of diabetes mellitus may include the attention of the specialists and consultants in the study. The specialists at Pinang General Hospital might play more attentions to the patients of diabetes mellitus. The other possible reason for the better control of diabetes mellitus in Pinang General Hospital as compared with the studies conducted elsewhere was the positive and welcoming attitude of doctors toward the recommendations of diabetes mellitus guidelines. The other possible reason for the good control of diabetes mellitus may include the patients' awareness and adherence of patients with the recommendations of management of diabetes mellitus. If the patients are more adhere with medication recommendations then there will be a better control (Karter et al., 2001; Anderson et al., 2002, Lewin et al., 2006; Simpson et al., 2006).

\section{CONCLUSION}

The present study exposed a fair to good level of adherence of doctors toward CPG 2009 recommendations in Penang General Hospital. More than two third patients were receiving compliance therapy with guidelines. Doctors having more knowledge possessed more adherences toward the recommendations of CPG 2009. Patients in diabetic ward and clinics are receiving more adherent therapy as compared with the other wards and clinics of Hospital. In contrast the patients in nephrology ward were receiving poor adherence therapy as compared with other wards of Penang General Hospital. It is challengeable to control the disease in nephrology ward; perhaps the poor adherence of doctors towards CPG 2009 might be the possible reason for poor control of diabetes mellitus in nephrology ward. The adherence and control of diabetes mellitus had a significant association.

\section{REFERENCES}

Agrawal, P., Arora, S., Singh, B., Manamalli, A. \& Dolia, P. B. (2011) Association of macrovascular complications of type 2 diabetes mellitus with serum magnesium levels. Diabetes \& Metabolic Syndrome: Clinical Research \& Reviews, 5, 4144. [DOI]

Ahmad, N., Hassan, Y., Tangiisuran, B., Meng, O. L., Aziz, N. A., Ahmad, F. U. D., \& Atif, M. (2012). Guidelines adherence and hypertension control at a tertiary hospital in Malaysia. Journal of Evaluation in Clinical Practice, 19(5). [DOI]

Ahmad, Nafees., Hassan, Y., Tangiisuran, B., Meng, O. L., Aziz, N. A., \& Khan, A. H. (2012). Guidelines Adherence and Hypertension Control in an Outpatient Cardiology Clinic in Malaysia. Tropical Journal of Pharmaceutical Research, 11(4), 665-672. [DOI]

Alberti, K. G. M. M. \& Zimmet, P. (1998) Definition, diagnosis and classification of diabetes mellitus and its complications. Part 1: Diagnosis and classification of diabetes mellitus. Provisional report of a who consultation. Diabetic medicine, 15, 539-553. [DOI]

Anderson, B., Vangsness, L., Connell, A., Butler, D., Goebel Fabbri, A. \& Laffel, L. (2002) Family conflict, adherence, and glycaemic control in youth with short duration type 1 diabetes. Diabetic medicine, 19, 635-642. [DOI]

Arauz-Pacheco, C., Parrott, M. A. \& Raskin, P. (2002) The treatment of hypertension in adult patients with diabetes. Diabetes Care, 25, 134-147. [DOI]

Beckman Ja, Creager MA, Libby P (2002) Diabetes and atherosclerosis: Epidemiology, pathophysiology, and management. Journal of American Medical Association, 287, 2570-2581. [DOI]

Chatterjee, J. (2006) From compliance to concordance in diabetes. Journal of medical ethics, 32, 507-510 [DOI]

Chuang, L. M., Tsai, S. T., Huang, B. Y. \& Tai, T. Y. (2002) The status of diabetes control in asia - a cross-sectional survey of 24317 patients with diabetes mellitus in 1998. Diabetic medicine, 19, 978-985. [DOI]

Coon, P. \& Zulkowski, K. (2002) Adherence to american diabetes association standards of care by rural health care providers. Diabetes Care, 25, 2224-2229. [DOI]
Cramer, J., Benedict, A., Muszbek, N., Keskinaslan, A. \& Khan, Z. (2008) The significance of compliance and persistence in the treatment of diabetes, hypertension and dyslipidaemia: A review. International journal of clinical practice, 62, 76-87. [DOI]

Fürthauer, J., Flamm, M., \& Sönnichsen, A. (2013). Patient and physician related factors of adherence to evidence based guidelines in diabetes mellitus type 2 cardiovascular disease and prevention: a cross sectional study. BMC family practice, 14(1), 47. [DOI]

Heisler, M., Bouknight, R. R., Hayward, R. A., Smith, D. M. \& Kerr, E. A. (2002) The relative importance of physician communication, participatory decision making and patient understanding in diabetes selfâ€ management. Journal of General Internal Medicine, 17, 243-252. [DOI]

Karter, A. J., Ackerson, L. M., Darbinian, J. A., D. Agostino Jr, R. B., Ferrara, A., Liu, J. \& Selby, J. V. (2001) Self-monitoring of blood glucose levels and glycemic control: The northern california kaiser permanente diabetes registry - . The American Journal of Medicine, 111, 1-9. [DOI]

Khan, A. T., Lateef, N. A., Khamseen, M. A. B., Alithan, M. A. A., Khan, S. A., \& Ibrahim, I. A. (2011). Knowledge, attitude and practice of ministry of health primary health care physicians in the management of type 2 diabetes mellitus: A cross sectional study in the Al Hasa District of Saudi Arabia, 2010. Nigerian journal of clinical practice, 14 (1), 52-59. [DOI]

Khattab, M., Khader, Y. S., Al-Khawaldeh, A. \& Ajlouni, K. (2010) Factors associated with poor glycemic control among patients with type 2 diabetes. Journal of Diabetes and its Complications, 24, 84-89. [DOI]

Kirkman, M. S., Williams, S. R., Caffrey, H. H. \& Marrero, D. G. (2002) Impact of a program to improve adherence to diabetes guidelines by primary care physicians. Diabetes Care, 25, 1946-1951. [DOI]

Lewin, A. B., Heidgerken, A. D., Geffken, G. R., Williams, L. B., Storch, E. A., Gelfand, K. M. \& Silverstein, J. H. (2006) The relation between family factors and metabolic control: The role of diabetes adherence. Journal of Pediatric Psychology, 31, 174-183. [DOI]

Nathan, D. M., Buse, J. B., Davidson, M. B., Ferrannini, E., Holman, R. R., Sherwin, R. \& Zinman, B. (2009) Medical management of hyperglycemia in type 2 diabetes: A consensus algorithm for the initiation and adjustment of therapy a consensus statement of the american diabetes association and the european association for the study of diabetes. Diabetes Care, 32, 193-203. [DOI]

Nazimek-Siewniak, B. A., Moczulski, D. \& Grzeszczak, W. A. A. (2002) Risk of macrovascular and microvascular complications in type 2 diabetes: Results of longitudinal study design. Journal of Diabetes and its Complications, 16, 271276. [DOI]

Peimani, M., Tabatabaei-Malazy, O., Heshmat, R., Moghaddam, S., Sanjari, M. \& Pajouhi, M. (2010) Knowledge, attitude and practice of physicians in the field of diabetes and its complications: A pilot study. Iran Journal of Diabetes and Lipid Disord, 9, 1-7.

Piette, J. D. \& Kerr, E. A. (2006) The impact of co-morbid chronic conditions on diabetes care. Diabetes Care, 29, 725-731. [DOI]

Redekop, W., Koopmanschap, M., Stolk, R., Rutten, G., Wolffenbuttel, B. \& Niessen L. (2002) Health-related quality of life and treatment satisfaction in dutch patients with type 2 diabetes. Diabetes Care, 25, 458 - 463. [DOI]

Satman, I., Imamoglu, S., \& Yilmaz, C. (2012). A patient-based study on the adherence of physicians to guidelines for the management of type 2 diabetes in Turkey. Diabetes research and clinical practice, 98 (1), 75-82. [DOI]

Schoenfeld, E. R., Greene, J. M., Wu, S. Y. \& Leske, M. C. (2001) Patterns of adherence to diabetes vision care guidelines: Baseline findings from the diabetic retinopathy awareness program. Ophthalmology, 108, 563-571. [DOI]

Simpson, S. H., Eurich, D. T., Majumdar, S. R., Padwal, R. S., Tsuyuki, R. T., Varney, J., \& Johnson, J. A. (2006). A meta-analysis of the association between adherence to drug therapy and mortality. BMJ, 333(7557), 15. [DOI]

Struijs, J. N., Baan, C. A., Schellevis, F. G., Westert, G. P., \& van den Bos, G. A. (2006). Co-morbidity in patients with diabetes mellitus: impact on medical health care utilization. BMC health services research, 6(1), 84. [DOI]

Ward, M. M., Vaughn, T. E., Uden Holman, T., Doebbeling, B. N., Clarke, W. R. \& Woolson, R. F. (2002) Physician knowledge, attitudes and practices regarding a widely implemented guideline. Journal of Evaluation in Clinical Practice, 8 , 155-162. [DOI]

Wermeling, P., Gorter, K., Van Stel, H. \& Rutten, G. (2012) Both cardiovascular and non-cardiovascular co-morbidity are related to health status in well-controlled type 2 diabetes patients: A cross-sectional analysis. Cardiovascular Diabetology, 11, page 121. [DOI]

Wexler, D., Grant, R., Wittenberg, E., Bosch, J., Cagliero, E. \& Delahanty, L. (2006) Correlates of health-related quality of life in type 2 diabetes. Diabetologia, 49 , 1489 - 1497. [DOI]

Yun, L. S., Hassan, Y., Aziz, N. A., Awaisu, A. \& Ghazali, R. (2007) A comparison of knowledge of diabetes mellitus between patients with diabetes and healthy adults: A survey from north malaysia. Patient education and counseling, 69, 4754. [DOI] 